\title{
Stress and musculoskeletal discomfort among hydrocarbon industry workers in Mexico
}

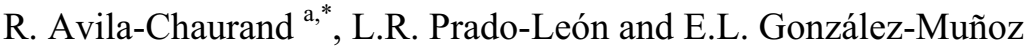 \\ ${ }^{a}$ Ergonomics Research Center. University of Guadalajara, Calzada Independencia Norte No. 5075, Huentitán El \\ Bajo, C.P. 44250. Guadalajara, Jal., México.
}

\begin{abstract}
This study of 114 workers in the hydrocarbon industry was conducted to identify the relationship between stress and musculoskeletal discomfort, and to view the roles played by such factors as age, schooling, obesity, workplace and job seniority. All factors except seniority were found to affect the presence of musculoskeletal discomfort in some area of the body.
\end{abstract}

Keywords: stress, musculoskeletal discomfort, hydrocarbon industry

\section{Introduction}

The objective of this research was to gauge levels of stress and musculoskeletal discomfort in a group of workers from the hydrocarbon processing industry, and their possible association with certain characteristics of workers' occupational and sociodemographic conditions. The study was carried out at two locations; one offshore platform and one on land.

Kraus [1] showed that in such companies work went on twenty-four hours a day, in 8- or 12-hour shifts, and that workers needed considerable experience, skill and energy in order to face the tough mental and physical job requirements. Because of these and other demands, attention must be paid to workers' moods as well as their health and safety. The main occupational risks related to this activity are illness from exposure to geographic and climatic elements, stress produced by having to travel long distances over water or rough terrain, and personal injuries. The physical isolation of the drilling grounds, their distance from base encampments and the long work days necessary on both offshore drilling platforms and remote onshore installations, may lead to psychological problems [1].

The presence of musculoskeletal injuries is also common among this type of worker. A study by Troconis, et al. [2] concluded that a high risk of mus- culoskeletal injuries exists for the majority of drilling platform workers, and that age and length of time on the job are significantly related to the presence of said risk.

There are various theories to explain the presence of musculoskeletal problems; all highlight the importance of psychosocial factors as they interact with physical exposure to heighten the probability of injury [3].

\section{Method}

A descriptive cross sectional study was done with 114 male workers at offshore and onshore hydrocarbon distribution sites. Average age was $42 \pm 11$ years, with an average $5 \pm 4$ years on the job. The sampling is non-random, with subjects chosen according to those who were working at the time and agreed to participate in the study.

Along with other data, anthropometric measurement obtained subjects' weight and height, from which was derived Body Mass index

Two questionnaires were applied, one to detect the presence of musculoskeletal discomfort and the other, the Job Content Questionnaire (JCQ) developed by Karasek [4], to detect levels of worker stress.

\footnotetext{
*Corresponding author. E-mail: rolexrachal@yahoo.com.mx
} 


\section{Results}

As for stress, it appeared in $15 \%$ of workers with no difference between onshore or offshore workers (Table 1).

Although musculoskeletal discomfort exists at both offshore and onshore installations, the variables with which it is associated are very different. On land, discomforts are linked to employment characteristics (seniority and shifts worked) as well as sociodemographic ones (age and schooling). At the maritime platform, on the other hand, there is more relation with sociodemographic features such as schooling and obesity. Obesity is related to musculoskeletal discomfort among workers at both land and sea installations, but it has different effects in each location, with the former manifesting more hip discomfort. For all, obesity is related to knee and ankle discomfort (Table 2 and 3 ).
Table 1

Subjects' characteristics related to musculoskeletal discomfort.

\begin{tabular}{llll}
\hline Stress & All & Onshore & Offshore \\
\hline No & 85.1 & 84.2 & 86 \\
\hline Yes & 14.9 & 15.8 & 14 \\
\hline
\end{tabular}

\section{Discussion}

Study results confirm the presence of stress and musculoskeletal discomfort among the workers evaluated, and obesity as a possibly significant factor in these conditions, along with job characteristics. Despite social isolation and 12-hour shifts at the maritime platform, stress levels were similar to those at the onshore installation: this aspect will require further research in subsequent studies, since studies in other countries have found higher stress levels among workers at offshore installations (R.S. Kraus, [1]). Given the high level of obesity observed, preventive worker health and safety plans should include programs with rigorous dietary and physical exercise components.

Table 2

Subjects' characteristics related to musculoskeletal discomfort

\begin{tabular}{|c|c|c|c|c|c|c|c|c|c|c|c|c|c|c|}
\hline & & & \multicolumn{3}{|c|}{ Neck } & \multicolumn{3}{|c|}{ Elbows } & \multicolumn{3}{|c|}{ Hips } & \multicolumn{3}{|c|}{ Knees } \\
\hline & & & $\mathrm{N}$ & ) & $X^{2}$ & $\mathrm{~N}$ & $\mathrm{Y}$ & $X^{2}$ & $\mathrm{~N}$ & $\mathrm{Y}$ & $X^{2}$ & $\mathrm{~N}$ & Y & $X^{2}$ \\
\hline & & & o & es & & o & es & & o & es & & o & es & \\
\hline \multirow{5}{*}{ All } & \multirow[b]{2}{*}{$\begin{array}{l}\text { Dichotomous } \\
\text { Age }\end{array}$} & $<40$ & & & & 45 & 0 & & 45 & 0 & & & & \\
\hline & & 40 or older & & & & 63 & 6 & $\begin{array}{c}4.13 \\
(0.05)\end{array}$ & 63 & 6 & $\begin{array}{c}4.13 \\
(0.05)\end{array}$ & & & \\
\hline & \multirow{3}{*}{ Obesity } & No & & & & & & & & & & 43 & 10 & \\
\hline & & Yes & & & & & & & & & & 39 & 21 & $\begin{array}{r}0.6 \\
(0.05)\end{array}$ \\
\hline & & Total & & & & & & & & & & 82 & 31 & \\
\hline \multirow{3}{*}{ Offshore } & \multirow{3}{*}{$\begin{array}{l}\text { High School } \\
\text { Diploma }\end{array}$} & No & & & & & & & & & & 33 & 7 & \multirow{3}{*}{$\begin{array}{c}7.42 \\
(0.01)\end{array}$} \\
\hline & & Yes & & & & & & & & & & 8 & 9 & \\
\hline & & Total & & & & & & & & & & 41 & 16 & \\
\hline
\end{tabular}


Table 3

Description of Subjects

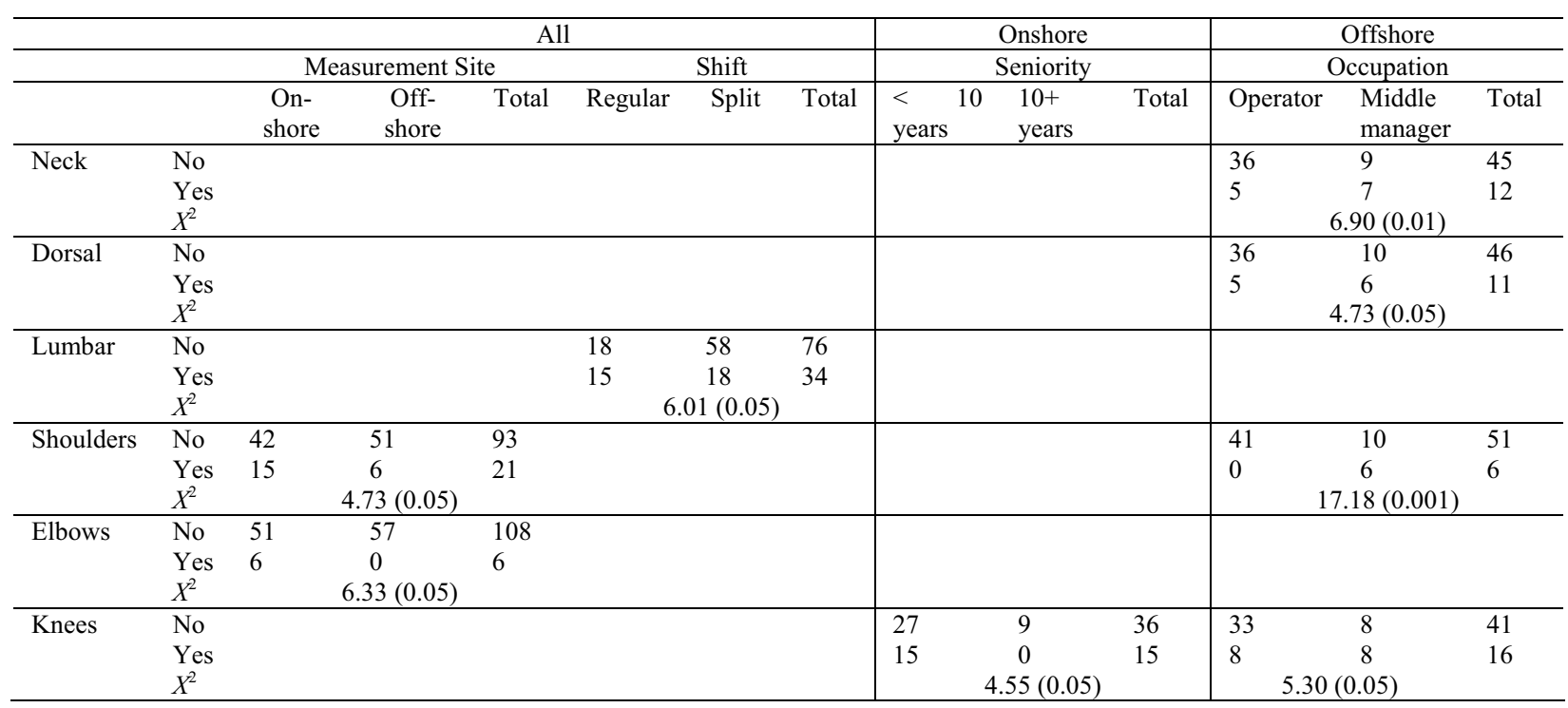

\section{References}

[1] R. S. Kraus, Ch. 75. Petróleo: prospección y perforación. In Enciclopedia de Salud y Seguridad en el Trabajo,

Organización Internacional del Trabajo, España, 2001.

[2] F. Troconis, A. Lubo M. Montiel, A. L. Quevedo, L. Rojas, B.

Chacin, et al. Valoración postural y riesgo de lesión músculo esquelética en trabajadores de una plataforma de perforación petrolera lacustre. (Study of postural and skeletal muscle damage in oil platform workers). Salud de los Trabajadores, 1 (2008), 29-38.

[3] B.T. Karsh, Theories of work-related musculoskeletal disorders: implications for ergonomics interventions, Theoretical Issues in Ergonomics Science 7 (2006), 71-88.

[4] R. Karasek, C. Brisson, N. Kawakami, I. Houtman, P. Bongers, \& B. Amick, The Job Content Questionnaire (JCQ): An instrument for internationally comparative assessments of psychosocial job characteristics. Journal of Occupational Health Psychology, 3, (1998). 322-355. 